Cite this: New J. Chem., 2014 38,3275

Received (in Montpellier, France) 28th February 2014,

Accepted 5th May 2014

DOI: 10.1039/c4nj00301b

www.rsc.org/njc

\title{
Surface area or diameter - which factor really determines the antibacterial activity of silver nanoparticles grown on $\mathrm{TiO}_{2}$ coatings?
}

\author{
K. Zawadzka, ${ }^{a}$ K. Kądzioła, ${ }^{b}$ A. Felczak, ${ }^{a}$ N. Wrońska, ${ }^{a}$ I. Piwoński, ${ }^{b}$ A. Kisielewska ${ }^{b}$ \\ and K. Lisowska*a
}

\begin{abstract}
Titanium dioxide coatings were prepared on Si wafers using the sol-gel method. Four different types of coatings with silver nanoparticles (AgNPs) were synthesized. The diameter and surface density of AgNPs were conditioned by the concentration of $\mathrm{Ag}^{+}$ions in the initial solution, time and UV illumination source. The bactericidal activity of AgNPs on the titanium dioxide coatings against the $S$. aureus strain were calculated as the percentage of the inhibition of bacterial growth after 24 hour incubation of microorganisms at $37{ }^{\circ} \mathrm{C}$ on $\mathrm{TiO}_{2}$ coatings with AgNPs. Control samples were coated with titanium dioxide without AgNPs. We concluded that the titanium dioxide coatings modified with silver nanoparticles had a high antibacterial activity. Moreover, we demonstrated strong dependence between surface areas of AgNPs and inhibition of bacterial growth. The obtained results evidence that the surface area of AgNPs grown on titanium dioxide coatings is a major factor determining their antimicrobial potential.
\end{abstract}

\section{Introduction}

The antibacterial properties of silver have been known for centuries, but the discovery of antibiotics led to the limitation of widespread use of this metal. ${ }^{1}$ The emergence of drugresistant bacteria that cause many human diseases and the development of nanotechnology resulted in renewed interest in the antimicrobial potential of silver. Nanosilver has unique physical, chemical and biological properties making it one of the most widely used nanomaterials in health care. ${ }^{1-3}$ In recent years AgNPs were used in cosmetic and food industries, many household products, and air and water purification systems. ${ }^{4}$ Many studies documented high antimicrobial potential of various types of AgNPs against yeasts, molds and Gram-positive and Gram-negative bacteria. ${ }^{5-10}$ Martinez-Gutierrez et al. evaluated the activity of silver nanoparticles of different size against Gram-positive (B. subtilis, M. bovis, M. smegmatis, S. aureus) and Gram-negative bacteria (A. baumanii, E. coli, P. aeruginosa) and fungi (A. niger, C. albicans, C. neoformans). The greatest antimicrobial activity against all tested microorganisms was exhibited by the smallest silver nanoparticles sized $20-25 \mathrm{~nm} .{ }^{11}$ AgNPs stabilized by poly(vinylpyrrolidone) showed strong antimicrobial activity toward

\footnotetext{
${ }^{a}$ Department of Industrial Microbiology and Biotechnology, Faculty of Biology and Environmental Protection, University of Lodz, 12/16 Banacha Street, 90-237 Lodz, Poland. E-mail: katalis@biol.uni.lodz.pl; Tel: +48 42 635-44-68

${ }^{b}$ Department of Materials Technology and Chemistry, Faculty of Chemistry,

University of Lodz, 163 Pomorska Street, 90-236 Lodz, Poland
}

bacteria, yeast and filamentous fungus Aspergillus brasiliensis. $^{12}$ In recent years many studies on titanium dioxide surfaces modified with different metals have been performed. Particular attention has been focused on AgNPs bound to $\mathrm{TiO}_{2}$ coatings. Ag- $\mathrm{TiO}_{2}$ composites are characterized by nontoxicity and high antimicrobial potential. Moreover, low cost preparation of the $\mathrm{Ag}-\mathrm{TiO}_{2}$ coating is their additional advantage. ${ }^{6}$ The silver-doped materials are of great interest due to their high chemical durability and long-term release of silver ions from the surface of these nanocomposites. ${ }^{13}$ Zhang and co-workers demonstrated strong antimicrobial properties of novel Ag-doped $\mathrm{TiO}_{2}$ nanosheet films against E. coli and $S$. aureus both under dark conditions and under UV light. ${ }^{9}$ The significant growth of interest in $\mathrm{TiO}_{2}$ materials has been caused by their nontoxicity, low cost, high chemical and physical stability, which makes them one of the most promising materials in selfcleaning and antibacterial applications. It has been shown that AgNPs doped to the $\mathrm{TiO}_{2}$ surface $\left(\mathrm{AgNPs}-\mathrm{TiO}_{2}\right)$ exhibit high antimicrobial potential. ${ }^{6}$ Zhang and Chen also demonstrated high antimicrobial potential against $E$. coli of $\mathrm{Ag}-\mathrm{TiO}_{2}$ nanocomposite powders synthesized by the one-pot sol-gel method. ${ }^{10}$ Moreover, $\mathrm{Ag}-\mathrm{TiO}_{2}$-cotton loaded textiles showed high antimicrobial potential against E. coli. ${ }^{14}$ Many researchers have been trying to identify factors determining the antimicrobial activity of AgNPs. ${ }^{8,13}$ Data suggest that one of these factors may be the size of nanoparticles. ${ }^{7,8}$ Xiu et al. reported that the bactericidal efficacy of AgNPs against Gram-negative bacteria $E$. coli depends on the particle size and concentration of released $\mathrm{Ag}^{+}$ions, since AgNPs with a small diameter release more silver ions. ${ }^{8}$ 
In our previous study we determined the influence of various parameters on the size and surface density of AgNPs grown on $\mathrm{TiO}_{2}$ surfaces under UV light. Moreover, we evaluated the correlation between the surface density of AgNPs per unit surface area of $\mathrm{TiO}_{2}$ coatings and the antibacterial efficiency against $S$. aureus. It was found that the antimicrobial activity was stronger with increasing number of AgNPs for $\mu^{2} \mathrm{TiO}_{2}$ coatings. ${ }^{15}$

In this work we investigated the antimicrobial activity against $S$. aureus of AgNPs on the titanium dioxide coatings synthesized by the sol-gel method. Furthermore, we analyzed the relationship between the surface area of AgNPs and their antimicrobial properties against Gram-positive bacteria of $S$. aureus. In order to achieve this goal the process of AgNPs growth was conducted in such a way as to obtain coatings with a low, medium and high surface area of metallic silver on the sol-gel $\mathrm{TiO}_{2}$ coating. The surface area was controlled by the size and surface density of AgNPs. Low surface area AgNPs-TiO coatings were obtained by growing a small number of small nanoparticles labeled SS. Medium surface area coatings were obtained by a small number of large nanoparticles and a large number of small nanoparticles and labeled SL and LS, respectively. Finally, a large surface area of silver was obtained for a large number of large nanoparticles and labeled LL.

\section{Results and discussion}

\section{Characterization of the AgNPs grown on $\mathrm{TiO}_{2}$ coatings}

Detailed parameters of four classes of coatings with various densities of AgNPs, which differ in size, thus having different surface areas are given in Table 1 . These parameters were calculated on the basis of AFM images. The preparation of such coatings was carried out towards obtaining nanoparticles with a size of about $d=15 \mathrm{~nm}$ and $d=80 \mathrm{~nm}$. These two classes of nanoparticles are well visible in the size distribution histograms shown in Table 1. Additionally, nanoparticles with low and high surface density (i.e. $n=2-3$ and $n=9-60$ AgNPs per $\mu \mathrm{m}^{2}$, respectively) having these sizes were obtained, enabling the control of the surface area of the AgNPs (Table 1, Fig. 1 and 2). In the case of large nanoparticles $(d=84 \mathrm{~nm})$, their surface density $\left(n=9 \mathrm{AgNPs}\right.$ per $\left.\mu \mathrm{m}^{2}\right)$ is much lower than for a corresponding sample with small nanoparticles $(d=15 \mathrm{~nm})$. This difference comes from the fact that they occupy more than 30 times larger surface area of $\mathrm{TiO}_{2}$.

AFM analysis of $\mathrm{TiO}_{2}$ and AgNPs-TiO 2 coatings enabled calculation of the number and diameter of AgNPs. Typical AFM images of $\mathrm{TiO}_{2}$ coatings revealed flat topographies without any defects and cracks (Fig. 1). The surface profile of the section of $l=4 \mu \mathrm{m}$ presented next to the AFM image shows that the difference in the " $z$ " direction (in height) is $2-3 \mathrm{~nm}$. In the case of AgNPs- $\mathrm{TiO}_{2}$ coatings the surface roughness is larger. For LS AgNP coatings the maximum difference in the " $z$ " profile on the same section of $l=4 \mu \mathrm{m}$ is $25 \mathrm{~nm}$. The surface density of AgNPs $\left(n>60\right.$ AgNPs per $\left.\mu \mathrm{m}^{2}\right)$ and their diameter $(d=15 \pm$ $4 \mathrm{~nm}$ ) were calculated on the basis of the analysis of this image (Fig. 1). Surface parameters of other coatings (SS, SL and LL) calculated using AFM images are gathered in Table 1.
Table 1 Surface density and diameter of AgNPs on the titania surfaces

Surface density AgNP

Samples [AgNPs per $\left.\mu \mathrm{m}^{2}\right]$ diameter $[\mathrm{nm}]$ Size distribution

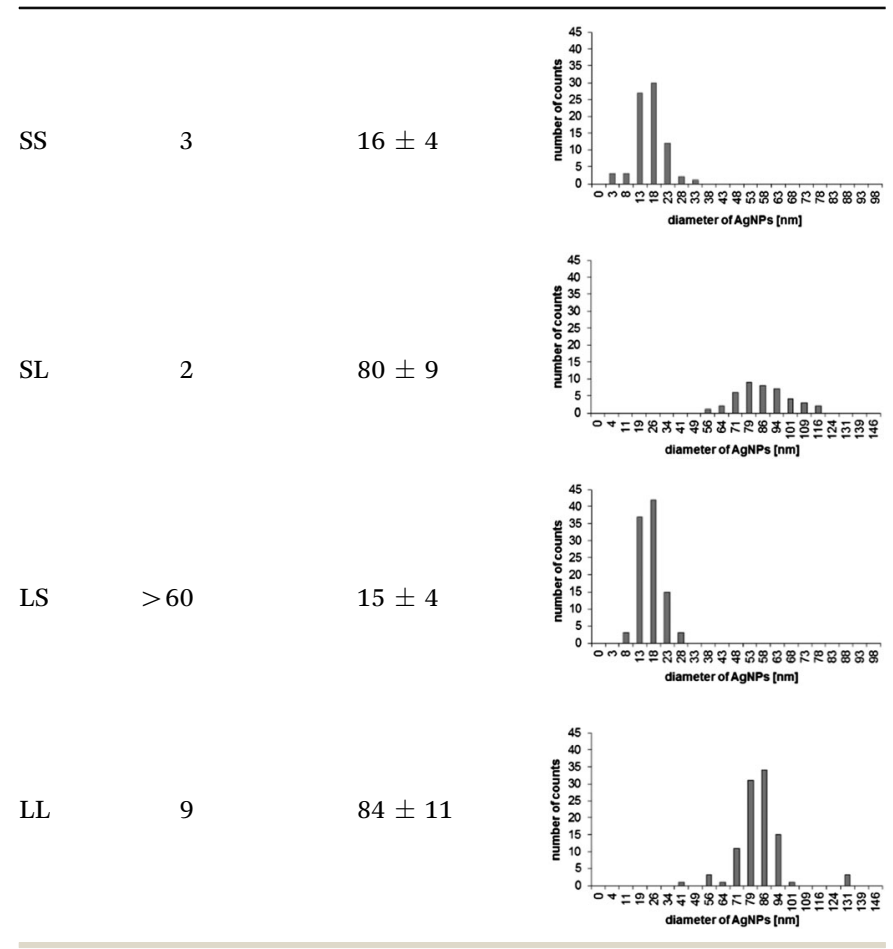

Further insight into the surface topography was obtained using scanning electron microscopy (SEM). Fig. 2 presents SEM images of the $\mathrm{TiO}_{2}$ control surface (Fig. 2A) and AgNPs grown on the $\mathrm{TiO}_{2}$ surface (Fig. 2B) after excimer laser illumination (LS sample). The average diameter of AgNPs calculated from the SEM images confirmed their size measured using AFM. For LS type of coating the diameter of AgNPs was $d=18 \mathrm{~nm}$. For other coatings the diameters of AgNPs calculated on the basis of SEM images were: $d=20 \mathrm{~nm}, d=80 \mathrm{~nm}$ and $d=84 \mathrm{~nm}$ for SS, SL and LL type of coatings, respectively. These results are the same as the results obtained from AFM measurements or are included within the error range. In turn, the SEM topography of the AgNPs- $\mathrm{TiO}_{2}$ coating after the antimicrobial study is shown in Fig. 2C. The image of the after-used material indicates that the AgNPs have not fallen off the $\mathrm{TiO}_{2}$ surface. However, their size and density are slightly lower than before antimicrobial tests. It means that part of silver from AgNPs was released as silver ions. Similar behavior was observed for all types of coatings (images not shown). This is in good agreement with the AAS analysis showing the presence of silver ions in the medium having direct contact with the AgNPs-TiO 2 coating in the range from $0.034 \mathrm{ppm}$ to $0.300 \mathrm{ppm}$ for SS and LL coatings respectively.

\section{Antimicrobial study of AgNPs grown on $\mathrm{TiO}_{2}$ coatings}

Liu et al. evaluated the bactericidal activity of mesoporus $\mathrm{TiO}_{2}$ and $\mathrm{Ag}-\mathrm{TiO}_{2}$ composite films and showed that the $\mathrm{Ag}-\mathrm{TiO}_{2}$ nanocomposite has better antimicrobial properties against Gram-negative bacteria E. coli than $\mathrm{TiO}_{2}$ alone. The researchers suggested that $\mathrm{Ag}-\mathrm{TiO}_{2}$ nanocomposites exhibit antimicrobial 
A

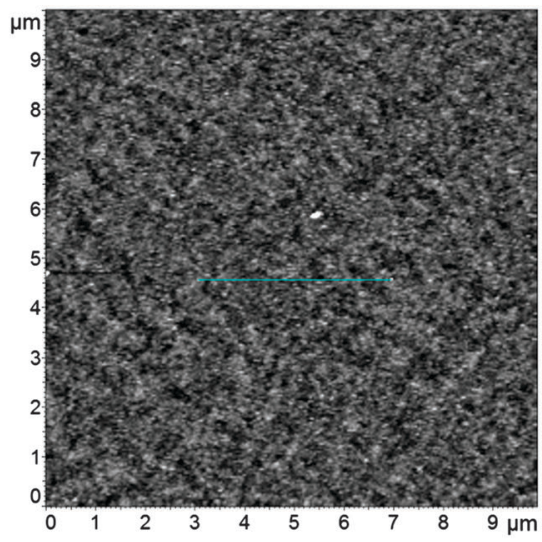

B

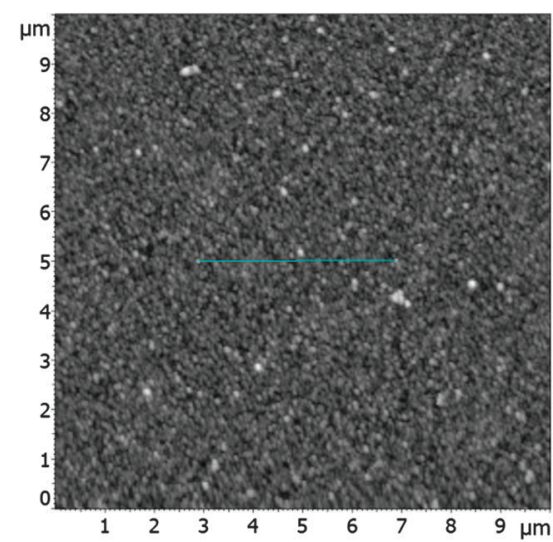

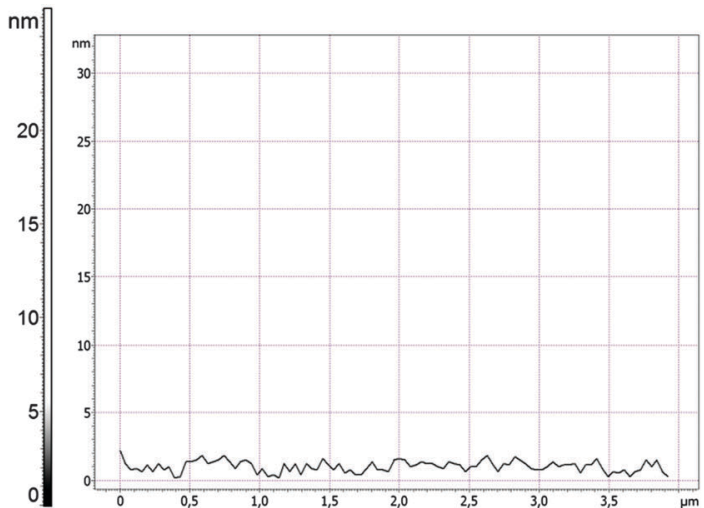

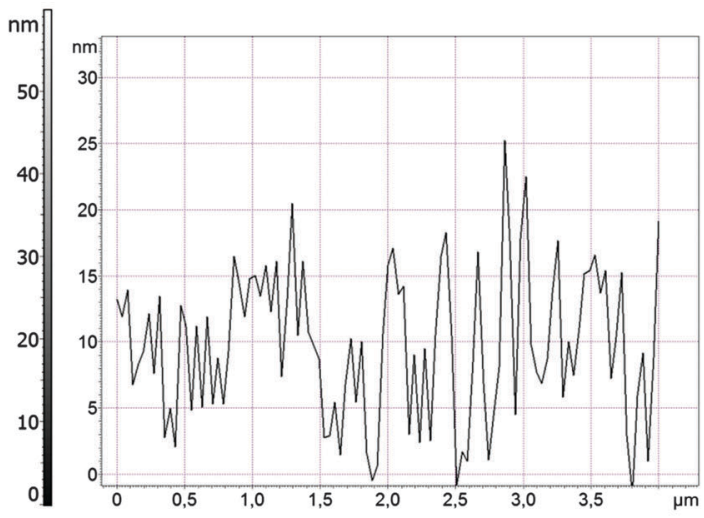

Fig. 1 AFM topography of the control $\mathrm{TiO}_{2}$ coating (A) and the $\mathrm{TiO}_{2}$ coating with a large number of small AgNPs (LS) (B) prepared using an excimer laser.

properties against tested bacteria and this activity depends on the nanoparticle size. ${ }^{16}$ Many researchers have attempted to explain the mechanism of antimicrobial activity of silver. ${ }^{13}$ The efficiency of silver nanoparticles against pathogens is determined by the large surface area of these clusters releasing large amounts of $\mathrm{Ag}^{+}$, which enables their interaction and penetration of the microbial cell membrane. AgNPs also interact with sulfur contained in membrane proteins and phosphorus contained in DNA. In this way they disrupt the operation of the respiratory chain and cell division after penetration into the cell and permanently lead to cell death. Many research groups report that the size and shape of silver nanoparticles have an influence on their antimicrobial activity. ${ }^{1}$ It was observed that the highest toxicity toward microorganisms is demonstrated by AgNPs with a small size. It is caused by a larger surface area and faster release of silver ions. ${ }^{8}$ Panáček et al. demonstrated the fungicidal activity of silver nanoparticles with a diameter of $25 \mathrm{~nm}$ against C. albicans. ${ }^{7}$ In other studies, the antibacterial activity of silver colloids nanoparticles was determined. The tested silver NPs with a diameter of 25-50 nm were prepared by the reduction of the $\left[\mathrm{Ag}\left(\mathrm{NH}_{3}\right)_{2}\right]^{+}$complex with saccharides. The antimicrobial potential of silver colloidal nanoparticles against Gram-positive and Gram-negative bacteria including drug resistant bacteria was studied. The strongest activity toward microorganisms was demonstrated by the smallest silver nanoparticles $(25 \mathrm{~nm}$-sized AgNPs). In contrast, the largest silver nanoparticles showed the lowest antibacterial properties. The authors brought out that the antibacterial effect of AgNPs depends on the nanoparticle size. ${ }^{17}$ Morones et al. investigated the bactericidal activity of AgNPs in the size range of 1-100 $\mathrm{nm}$ and showed that the higher antimicrobial activity against Gram-negative bacteria was expressed by silver nanoparticles of diameter $1-10 \mathrm{~nm} \cdot{ }^{18}$ Lu et al. studied the activity of AgNPs with a different particle size against anaerobic and aerobic bacteria. The smallest silver nanoparticles (5 $\mathrm{nm}$ AgNPs) exhibited the best antimicrobial performance. ${ }^{19}$ In another study also the smallest AgNPs $(20 \mathrm{~nm})$ demonstrated the highest effectiveness against Gram-negative $E$. coli bacteria. However, the analysis of the influence of the total surface area of silver nanoparticles on their antibacterial activity showed that the surface area and not the nanoparticle size determines the high antimicrobial potential. All tested sizes of AgNPs (20, 50, $110 \mathrm{~nm}$ ) caused identical 100\% inhibition of bacterial growth when their total surface area amounted to $1 \times 10^{18} \mathrm{~nm}^{2} \mathrm{~L}^{-1} \cdot{ }^{20}$ In our previous study, we demonstrated that the inhibition of S. aureus growth by $\mathrm{Ag}-\mathrm{TiO}_{2}$ coatings depends on the surface density of silver nanoparticles for AgNPs with a certain diameter. ${ }^{15}$ In this paper, the antibacterial activity of the $\mathrm{Ag}-\mathrm{TiO}_{2}$ plates was evaluated by the inhibition of growth of Gram-positive bacteria Staphylococcus aureus ATCC 6538. The obtained results are shown in Fig. 3. Plates coated with titanium dioxide exhibited mild antimicrobial properties against $S$. aureus. The data received by Aghavan demonstrated low antimicrobial 

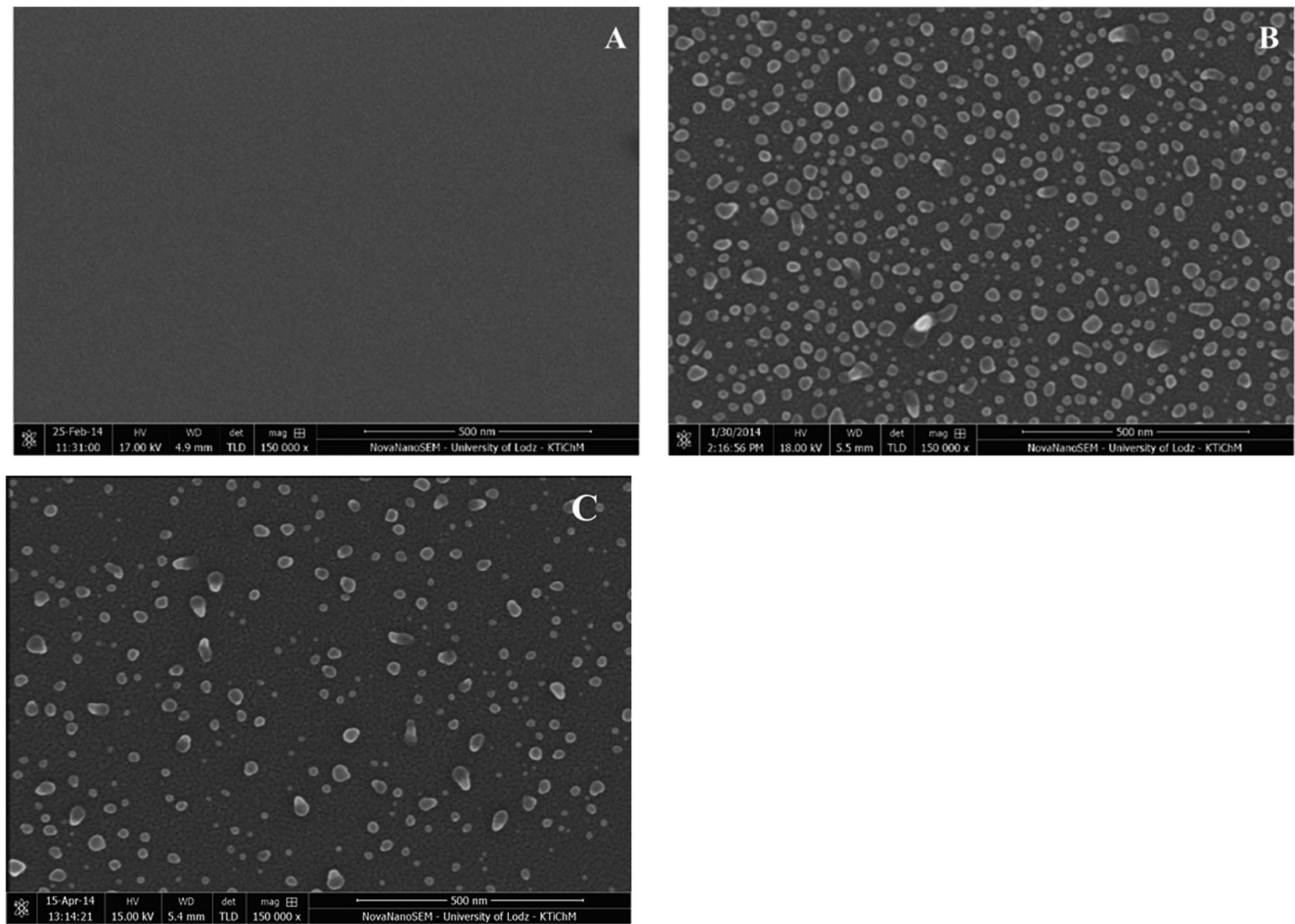

Fig. $2 \mathrm{SEM}$ images of the control $\mathrm{TiO}_{2}$ coating (A), the $\mathrm{TiO}_{2}$ coating with a large number of small AgNPs (LS) prepared using an excimer laser (B) and the LS coating after antimicrobial tests (C).

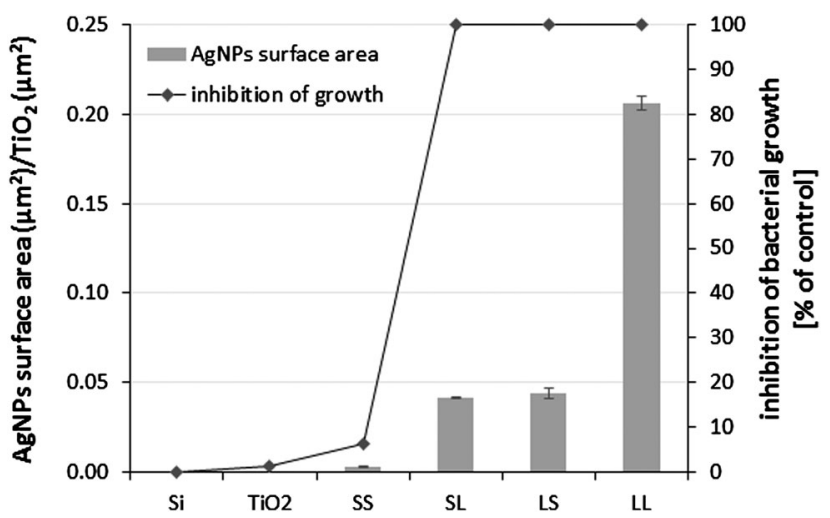

Fig. 3 Correlation between the surface area of AgNPs and inhibition of Staphylococcus aureus growth after $24 \mathrm{~h}$ incubation on the titanium dioxide coatings with silver nanoparticles.

activity of $\mathrm{TiO}_{2}$ thin films against E. coli. ${ }^{21}$ The results concerning the antibacterial activity of $\mathrm{TiO}_{2}$ are also consistent with the data presented by Perkas et $a .^{22}$ The determination of silicon plates coated with $\mathrm{TiO}_{2}$ and $\mathrm{Ag}$ nanoparticles revealed their strong antimicrobial activity toward $S$. aureus. We checked the influence of the surface density, the nanoparticle diameter and the surface area on the antimicrobial activity of the tested AgNPs-TiO ${ }_{2}$ coatings. The weakest properties were exhibited by the coating with a small number of small silver nanoparticles (SS). For the SS samples the inhibition of $S$. aureus growth reached a value of $6.5 \%$. In the case of the LS, SL and LL samples, which had AgNPs with a total surface area larger than $0.04 \mu \mathrm{m}^{2}$ per $1 \mu \mathrm{m}^{2} \mathrm{TiO}_{2}$, we observed $100 \%$ inhibition of S. aureus growth. The surface areas of AgNPs of LS and SL or LL samples were, respectively, 7 or 29 times larger than those of SS samples. The coatings with a small number of large AgNPs (SL) and a large number of small AgNPs (LS) had identical antimicrobial activity despite differences in the diameter of AgNPs and their surface density. These results indicate that the surface area of nanoparticles has the greatest impact on the efficiency of AgNPs activity against bacteria. The obtained results can suggest that an increase in the surface area is accompanied by a higher release of silver ions.

Damage to the $S$. aureus cell membrane was examined in order to confirm the antibacterial properties of tested AgNPs$\mathrm{TiO}_{2}$ coatings. Propidium iodide (PI), due to the held electric charge, does not cross the intact membrane of bacterial cells. However, it stains the cells with a damaged cytoplasmic membrane red, and thus allows evaluating their mortality. ${ }^{23}$ 

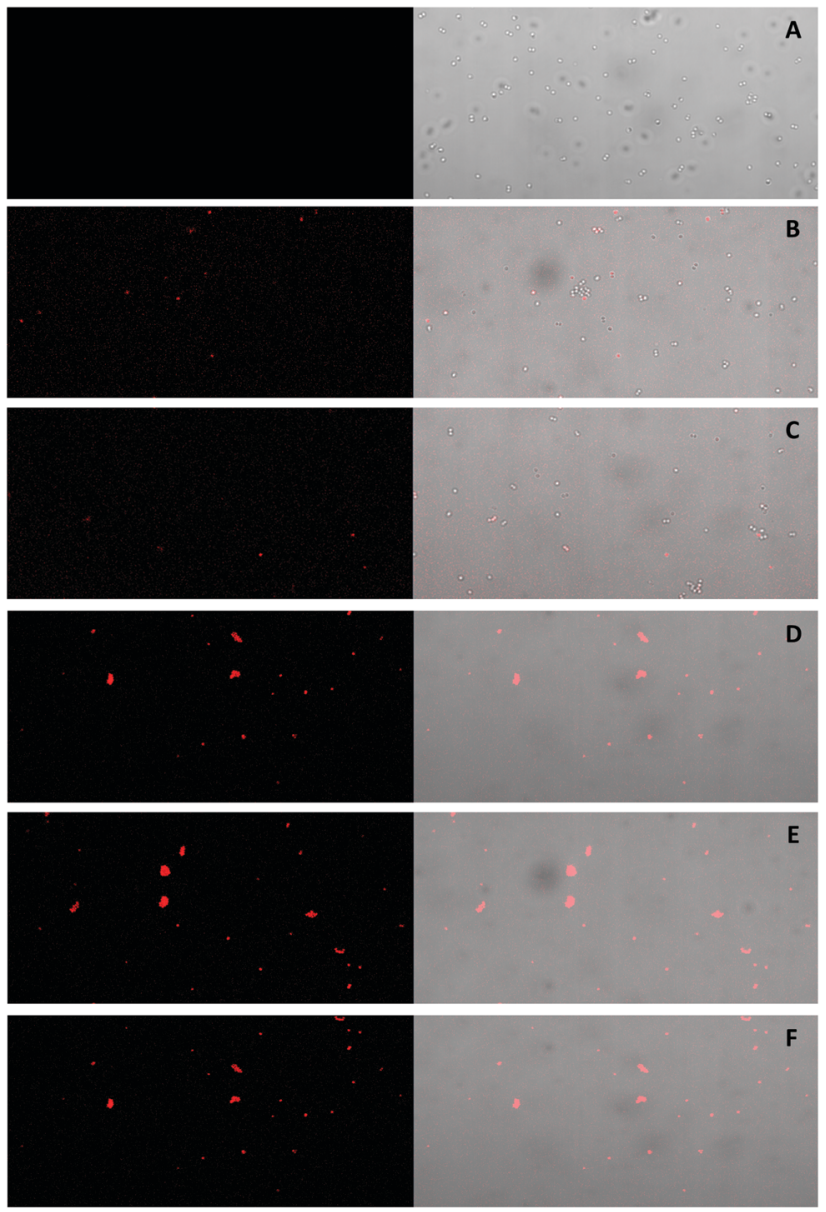

Fig. 4 Permeability of the $S$. aureus cell membrane after the treatment with silver nanoparticles (A) Si, (B) $\mathrm{TiO}_{2}$, (C) SS, (D) SL, (E) LS, (F) LL.

Shi et al. used PI staining to determine the viability of bacteria after the treatment with derivative chitosan nanoparticles (QCS $\mathrm{NP}$ ) in bone cement. The authors demonstrated a considerable increase in the mortality of $S$. aureus when chitosan was added in a nanoparticle form. A large number of $S$. aureus cells with disrupted cell membranes were observed in the case of QCS nanoparticles. ${ }^{24}$ Zhao and co-workers used a similar method to show the ability of small molecule-capped gold nanoparticles to disintegrate the bacterial membrane. ${ }^{25}$ We performed confocal microscopy and propidium iodide staining of $S$. aureus cells after their incubation on the coatings with silver nanoparticles $\left(\right.$ AgNPs-TiO $\left.{ }_{2}\right)$ and control samples $\left(\mathrm{Si}\right.$ and $\left.\mathrm{TiO}_{2}\right)$ to assess damage to the bacterial membrane. Our results confirm the strong antibacterial activity of SL, LS and LL coatings, because all microorganisms per microscope field were stained red by propidium iodide. In the case of $\mathrm{SS}$ and $\mathrm{TiO}_{2}$ samples we observed staining of only a few $S$. aureus cells. Bacterial cells which were incubated on silicon wafers did not take up the red color from PI (Fig. 4). For these reasons, we conclude that the higher surface area of silver nanoparticles increases the amount of released silver ions which significantly raise the mortality rate of $S$. aureus bacteria compared to the coatings with a small AgNP surface area.
Table 2 The amount of silver ions released from $\mathrm{AgNPs}-\mathrm{TiO}_{2}$

\begin{tabular}{ll}
\hline Samples & $\begin{array}{l}\text { The concentration } \\
\text { of } \mathrm{Ag}^{+} \text {ions }[\mathrm{ppm}]\end{array}$ \\
\hline $\mathrm{TiO}_{2}$ & 0.000 \\
$\mathrm{SS}$ & 0.034 \\
$\mathrm{SL}$ & 0.128 \\
$\mathrm{LS}$ & 0.107 \\
$\mathrm{LL}$ & 0.300
\end{tabular}

The concentration of silver ions released from AgNPs-TiO was determined in order to demonstrate the influence of the surface area of AgNPs grown on $\mathrm{TiO}_{2}$ coatings on their antibacterial activity. The highest concentration of released silver ions of $0.300 \mathrm{ppm}$ was observed in the sample with the highest surface area of AgNPs (LL). In contrast, the lowest concentration of silver ions released $(0.034 \mathrm{ppm})$ was noted for the samples with the lowest surface area of AgNPs (SS), which showed the weakest antimicrobial properties. For samples SL and LS, which have similar surface areas and antibacterial activity, the concentrations of $\mathrm{Ag}^{+}$ions released from AgNPs were similar and amounted to 0.128 and $0.107 \mathrm{ppm}$, respectively. On the basis of the obtained results, we conclude that the surface area of AgNPs determines the amount of silver ions released from nanoparticles and their activity against bacteria. Thus, the surface area of silver nanoparticles is a more important factor in the determination of their antibacterial activity than the diameters of the AgNPs (Table 2).

\section{Conclusions}

We demonstrated the high potential against Gram-positive $S$. aureus bacteria of silver nanoparticles attached to the titanium dioxide coating prepared using the sol-gel method. A correlation between the surface area of silver nanoparticles and their antimicrobial activity was observed. AgNPs with a large surface area are characterized by great inhibition of the growth of tested bacteria. These results indicate that the surface areas of $\mathrm{AgNPs}$ bound to $\mathrm{TiO}_{2}$ coatings determine the antimicrobial activity of these clusters. In our opinion the surface area of AgNPs grown on $\mathrm{TiO}_{2}$ coatings is a more significant factor in the determination of their antibacterial properties than the diameter of silver nanoparticles. The mechanism of the antibacterial activity of $\mathrm{TiO}_{2}$ coatings with silver nanoparticles will be a subject of study in the future.

\section{Experimental}

\section{Materials}

One side polished silicon $\mathrm{Si}(100)$ wafers were purchased from Cemat Silicon S.A. Poland. Titanium tetraisopropoxide (Aldrich, 97\%), isopropanol ( $\mathrm{POCH}$, pure, min 99.5\%), and silver nitrate (POCH, pure, 99.8\%) were purchased as guaranteed-grade reagents and used without further purification. $2 \mathrm{M}$ hydrochloric acid was prepared from concentrated hydrochloric acid (Chempur, pure). Silver nitrate solutions were prepared using water purified 
by the Millipore Simplicity UV system $\left(18.2 \mathrm{M} \Omega \mathrm{cm}\right.$ at $\left.25{ }^{\circ} \mathrm{C}\right)$. Antibacterial studies were performed using Millipore Milli Q RG water. Staphylococcus aureus ATCC 6538 were purchased from ATCC (USA).

\section{Preparation of titanium dioxide coatings}

Titanium dioxide coatings were deposited on silicon wafers using the sol-gel dip-coating method. In a typical procedure, $1.246 \mathrm{ml}(4.22 \mathrm{mmol})$ of titanium tetraisopropoxide and $0.0399 \mathrm{ml}$ of $2 \mathrm{M}(1.10 \mathrm{mmol})$ hydrochloric acid were added dropwise to $16.92 \mathrm{ml}$ of isopropanol $(220 \mathrm{mmol})$. The mixture was stirred for $30 \mathrm{~min}$ at room temperature. After that time, the silicon wafers were immersed into the sol using a computercontrolled dip-coater (NIMA Technology LB, UK) operating at an immersion and withdrawal velocity of $25 \mathrm{~mm} \mathrm{~min}^{-1}$. The obtained sol-gel coatings were heated at $100{ }^{\circ} \mathrm{C}$ for $2 \mathrm{~h}$ in order to remove residues of the solvent and subsequently calcined at $500{ }^{\circ} \mathrm{C}$ for $2 \mathrm{~h}$ in order to obtain an anatase phase. The heating rate was $6.67{ }^{\circ} \mathrm{C} \min ^{-1}\left(100{ }^{\circ} \mathrm{C} / 15 \mathrm{~min}\right)$.

\section{UV lamp}

The photocatalytic deposition of silver nanoparticles was performed using a $2 \times 15 \mathrm{~W}$ UV-lamp (UV-Consulting Peschl, wavelength $\lambda=365 \mathrm{~nm}$ ). The power density measured by us on

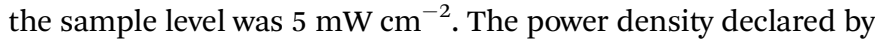
the producer was $2.3 \mathrm{~mW} \mathrm{~cm}{ }^{-2}$. The surface of $\mathrm{TiO}_{2}$ coatings and UV-rays were perpendicular during illumination. The distance between the samples and the light source was fixed at $20 \mathrm{~cm}$.

\section{Excimer laser}

A COMPex 201 excimer laser (Lambda-Physik) operating at $\lambda=$ $351 \mathrm{~nm}$ was used. The illumination was carried out in quartz cuvettes (pathlength $l=1 \mathrm{~cm}$, China). The number of impulses was set up for 100 . The time duration of one impulse was $22 \mathrm{~ns}$.

\section{In situ preparation of silver nanoparticles on the titanium dioxide surface}

Silver nitrate solutions with appropriate concentrations were prepared in deionized water. Titanium dioxide coatings were immersed into $2 \mathrm{ml}$ of silver nitrate solution and illuminated by UV light. Four types of coatings with AgNPs having various diameters and surface densities, along with one $\mathrm{TiO}_{2}$ coating without silver were prepared. Si wafers were used as reference samples. Coatings with silver were prepared in such a way as to obtain a small number of large AgNPs, a large number of large AgNPs, a large number of small AgNPs and a small number of small AgNPs. These samples were labeled SS, SL, LS and LL, respectively. Experimental details are given in Table 3.

\section{Atomic force microscopy surface imaging}

The surface topography of $\mathrm{TiO}_{2}$ coatings with AgNPs was imaged in the tapping mode using an NT-MDT microscope equipped with a Smena head operating under ambient conditions. NSC35/ $/ \mathrm{Si}_{3} \mathrm{~N}_{4} / \mathrm{AIBS}$ (MicroMasch) cantilevers or NSG 11 Golden Silicon Probes (NT-MDT) were used. A typical scan size of the image was $5 \mu \mathrm{m} \times 5 \mu \mathrm{m}$. The data of the AFM surface
Table 3 Parameters applied in the preparation of $\mathrm{TiO}_{2}$ coatings with AgNPs having various diameters and surface densities

\begin{tabular}{|c|c|c|c|}
\hline $\begin{array}{l}\text { Type of } \\
\text { coating }\end{array}$ & $\begin{array}{l}\mathrm{Ag}^{+} \text {concentration } \\
{[\mathrm{mmol}]}\end{array}$ & $\begin{array}{l}\text { Time of } \\
\text { illumination } \\
\text { [min] }\end{array}$ & $\begin{array}{l}\text { UV illumination } \\
\text { source }\end{array}$ \\
\hline SS & 0.05 & 1 & Lamp, $\lambda=365 \mathrm{~nm}$ \\
\hline SL & 0.05 & 60 & Lamp, $\lambda=365 \mathrm{~nm}$ \\
\hline LS & 1.00 & 100 impulses $^{a}$ & Excimer laser $\lambda=351 \mathrm{~nm}$ \\
\hline LL & 1.00 & 60 & Lamp, $\lambda=365 \mathrm{~nm}$ \\
\hline
\end{tabular}

topography were analyzed using the Image Analysis 2.2.0 SPM software (NT-MDT). The surface density (the density of nanoparticles per $\mu \mathrm{m}^{2}$ ) was calculated using an option available in the Image Analysis software. The size of the nanoparticles was calculated by measuring the height of 100 randomly chosen nanoparticles in an AFM image $(5 \mu \mathrm{m} \times 5 \mu \mathrm{m})$. In the case of coatings with a small number of AgNPs this value was lower. The average value from five independent measurements is presented. The surface area of AgNPs was calculated based on the assumption that they have a spherical shape. Knowing the surface area of an individual nanoparticle from the formula $S=4 \pi(d / 2)^{2}$ (where $d$ is the diameter of the nanoparticle) and the number of nanoparticles on one $\mu \mathrm{m}^{2}$, the surface area was calculated.

\section{Scanning electron microscopy surface imaging}

Scanning electron microscopic (SEM) analysis was performed on $\mathrm{TiO}_{2}$ and AgNPs-TiO ${ }_{2}$ coatings using a Schottky Field Emission Scanning Electron Microscope (FESEM), FEI apparatus, model Nova NanoSEM 450. Images were acquired in the immersion mode using a through lens detector (TLD) at a magnification of $150000 \times$.

\section{Determination of the antimicrobial activity of analyzed plates}

The antimicrobial activity of AgNPs- $\mathrm{TiO}_{2}$ coatings against Staphylococcus aureus ATCC 6538 was evaluated according to Piwoński et al. (2011) using the Japanese Industrial Standard JIS Z 2801:2000. Gram-positive bacteria of Staphylococcus aureus were cultured on Luria Bertani (LB) medium at $37^{\circ} \mathrm{C}$ on a rotary shaker. After the incubation the test inoculum of $S$. aureus containing $1 \times 10^{5}$ colony forming units (CFU per $\mathrm{ml}$ ) in 500fold diluted LB-medium was prepared. Next, the suspension of bacteria was applied to titania coatings with silver nanoparticles of $0.5 \mathrm{~cm} \times 1 \mathrm{~cm}$. Titanium dioxide $\left(\mathrm{TiO}_{2}\right)$ coatings were analyzed as control samples. After dripping the suspension of $S$. aureus on the coatings, each sample was covered with a sterile film $(0.7 \mathrm{~cm} \times 1.2 \mathrm{~cm})$. Then, the samples were incubated in the moist chamber in the dark for $24 \mathrm{~h}$ at $37^{\circ} \mathrm{C}$. After incubation the plates with the bacterial suspension and films were put in aseptic eppendorfs containing phosphate buffer and vortexed. Next, films and coatings were removed from the eppendorfs and with the remaining solution a serial dilution was performed in the phosphate buffer. Out of each dilution $100 \mu \mathrm{l}$ of bacterial suspension was seeded on an agar plate and incubated for $24 \mathrm{~h}$ at $37{ }^{\circ} \mathrm{C}$. After incubation viable cells of $S$. aureus were counted. Each type of $\mathrm{AgNPs}^{-\mathrm{TiO}_{2}}$ 
coatings (SS, SL, LS, LL) was examined in triplicate and analyzed individually in four independent experiments. The antimicrobial activity of the tested coatings was calculated as the percentage of bacterial growth inhibition $( \pm \mathrm{SD})$ toward control plates without the silver particles.

\section{Permeability of $S$. aureus cell membranes}

Bacterial cells obtained after the treatment with $\mathrm{Si}, \mathrm{TiO}_{2}$ and AgNPs-TiO 2 were washed thrice with phosphate buffer and stained with $3 \mathrm{mM}$ propidium iodide for $15 \mathrm{~min}$ at room temperature in the dark. S. aureus cells after incubation with PI were washed thrice with PBS and $20 \mu \mathrm{l}$ of the bacterial suspensions was mounted on a microscopic slide.

\section{Confocal microscopy}

A confocal Laser Scanning Microscope (Pascal 2, Zeiss) combined with an Axiovert 200M (Zeiss, Germany) inverted fluorescence microscope equipped with a Plan-Apochromat objective (63_/1.25 Oil) was used to obtain the images. The fluorescence of propidium iodide was detected using a He-Ne laser (543 nm) and a LP filter set (560-615 $\mathrm{nm}$ ) and the Nomarski DIC sections were done at an excitation of $488 \mathrm{~nm}$ of an argon laser.

\section{Release of silver ions from $\mathrm{AgNPs}^{-\mathrm{TiO}_{2}}$}

Atomic absorption spectrophotometry was performed to determine the concentration of silver ions released from $\mathrm{AgNPs}^{-\mathrm{TiO}_{2}}$. The AgNPs-TiO ${ }_{2}$ coatings were immersed in $1.5 \mathrm{ml}$ doubly distilled water for $24 \mathrm{~h}$ at $37{ }^{\circ} \mathrm{C}$. After incubation the coating was removed from the water, and the liquid was acidified with $65 \%$ nitric acid. The concentration of $\mathrm{Ag}^{+}$was measured using a Varian SpectrAA 300 Flame Atomic Absorption Spectrophotometer.

\section{Acknowledgements}

This work was supported by the Ministry of Science and Higher Education, the Republic of Poland, project number N N507 497538.

\section{References}

1 M. Rai, A. Yadav and A. Gade, Biotechnol. Adv., 2009, 27, 76.

2 G. A. Sotiriou and S. E. Pratsinis, Environ. Sci. Technol., 2010, 44, 5649.

3 B. Nowack, H. F. Krug and M. Height, Environ. Sci. Technol., 2011, 45, 1177.

4 C. Marambio-Jones and E. M. V. Hoek, J. Nanopart. Res., 2010, 12, 1531.
5 B. Yu, K. M. Leung, Q. Guo, W. M. Lau and J. Yang, Nanotechnology, 2011, 22, 1.

6 D. Wodka, E. Bielańska, R. P. Socha, M. Elżbieciak-Wodka, J. Gurgul, P. Nowak, P. Warszyński and I. Kumakiri, ACS Appl. Mater. Interfaces, 2010, 2, 1945.

7 A. Panáček, M. Kolár, R. Vecerová, R. Prucek, J. Soukupová, V. Krystof, P. Hamal, R. Zboril and L. Kvítek, Biomaterials, 2009, 30, 6333.

8 Z. M. Xiu, Q. B. Zhang, H. L. Puppala, V. L. Colvin and P. J. Alvarez, Nano Lett., 2012, 12, 4271.

9 Q. Zhang, C. Sun, Y. Zhao, S. Zhou, X. Hu and A. Chen, Environ. Sci. Technol., 2010, 44, 8270.

10 H. Zhang and G. Chen, Environ. Sci. Technol., 2009, 43, 2905.

11 F. Martinez-Gutierrez, P. L. Olive, A. Banuelos, E. Orrantia, N. Nino, E. Morales Sanchez, F. Ruiz, H. Bach and Y. Av-Gay, Nanomedicine, 2010, 6, 681.

12 R. Bryaskova, D. Pencheva, S. Nikolov and T. Kantardjiev, J. Chem. Biol., 2011, 4, 185.

13 H. J. Jeon, S. C. Yi and S. G. Oh, Biomaterials, 2003, 24, 4921. 14 T. Yuranova, A. G. Rincon, C. Pulgarin, D. Laub, N. Xantopoulos, H.-J. Mathieu and J. Kiwi, J. Photochem. Photobiol., A, 2006, 181, 363.

15 I. Piwoński, K. Kądzioła, A. Kisielewska, K. Soliwoda, M. Wolszczak, K. Lisowska, N. Wrońska and A. Felczak, Appl. Surf. Sci., 2011, 257, 7076.

16 Y. Liu, X. Wang, F. Yang and X. Yang, Microporous Mesoporous Mater., 2008, 114, 431.

17 A. Panácek, L. Kvítek, R. Prucek, M. Kolár, R. Vecerová, N. Pizúrova, V. K. Sharma, T. Nevěčná and R. Zbořil, J. Phys. Chem. B, 2006, 110, 16248.

18 J. R. Morones, J. L. Elechiguerra, A. Camacho, K. Holt, J. B. Kouri, J. T. Ramirez and M. J. Yacaman, Nanotechnology, 2005, 16, 2346.

19 Z. Lu, K. Rong, J. Li, H. Yang and R. Chen, J. Mater. Sci.: Mater. Med., 2013, 24, 1465.

20 C. R. Bowman, F. C. Bailey, M. Elrod-Erickson, A. M. Neigh and R. R. Otter, Environ. Toxicol. Chem., 2012, 31, 1793.

21 O. Akhavan, J. Colloid Interface Sci., 2009, 336, 117.

22 N. Perkas, A. Lipovsky, G. Amirian, Y. Nitzan and A. Gedanken, J. Mater. Chem. B, 2013, 1, 5309.

23 H. Sträuber and S. Müller, Cytometry, Part A, 2010, 77A, 623.

24 Z. Shi, K. G. Neoh, E. T. Kang and W. Wang, Biomaterials, 2006, 11, 2440.

25 Y. Zhao, Y. Tian, Y. Cui, W. Liu, W. Ma and X. Jiang, J. Am. Chem. Soc., 2010, 132, 12349. 